\title{
Work quality assessment of a cherry sorting machine
}

\author{
Ancza, E. ${ }^{1}$, Csizmazia, Z. ${ }^{1}$, Polyák, N. I. ${ }^{1}$, Farkas, E. ${ }^{2}$, Nyéki, J. ${ }^{1}$ \& Szabó, Z. ${ }^{1}$ \\ ${ }^{1}$ University of Debrecen Centre for Agricultural and Applied Economic Sciences, \\ H-4032 Debrecen, Böszörményi út 138., Hungary, E-mail: ancza@agr.unideb.hu \\ ${ }_{2}^{2}$ Alma 2000 Ltd., Almasétány 1., Nagykutas, 8911 Hungary
}

Summary: The conditions of the cultivation of marketable cherries are diverse. Choosing the production site on the basis of the climatic conditions, selecting the most appropriate variety taking into account the region and the purpose of the production, utilization of the optimal production method, to ensure the required water and nutrients supply, frost and hail protection techniques, modern technology in crop protection, and professional performance of harvesting and handling, to name just a few of the most important issues. The objective of present study is to determine the qualitative characteristics of the UNITEC cherry sorting machine.

Keywords: cherry sorting and grading, size measurements, mass distribution, stone-pulp ratio

\section{Cherry harvesting}

The edible, marketable crop is harvested manually from the ground, using low and high stands (Fig. 1). In plantations where there is no hail protection, so damaged fruit can occur, the picking is combined with pre-selection. In order to safeguard the quality, after the takeover of the controlled crops, it is practical to transport them in bins (Fig. 2).

\section{Grading of the cherry}

The sufficiently cooled product, to avoid damages, can be loaded manually from the bins to the three, sectioned feeder belts of the cherry sorting machine (Fig. 3). The examined type is the UNITEC, Italian cherry sorting machine. It is desirable to keep track of the number of steps and the number of people the fruits are selected by, to ensure that the end result is an intact, marketable crop. The pre-selection is made beside the feeder belts, and there are two additional workers with the person who uploads belts.

The product then transported from the feeder belts to three longitudinal sorting belts (Fig. 4), during which it is washed by water. The sorting belts are plain belts, so the workers have to stir the fruit so that the damaged ones can be seen. Eight people work beside each longitudinal sorting belts.

From the longitudinal sorting belts the fruit gets to a transverse collecting belt (Fig. 5), where the sorting is continued with nine people. The collecting belt arranges the fruit persistently to the preparatory phase of the ranking belt.

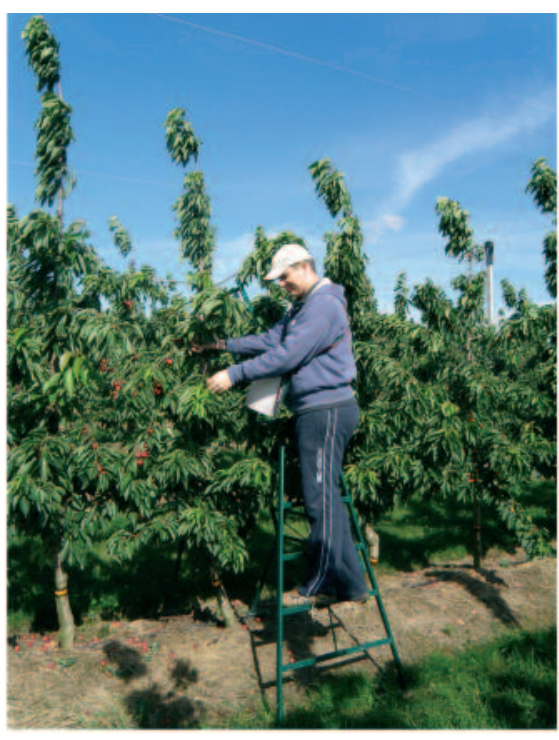

Fig. 1: Manual method of harvesting

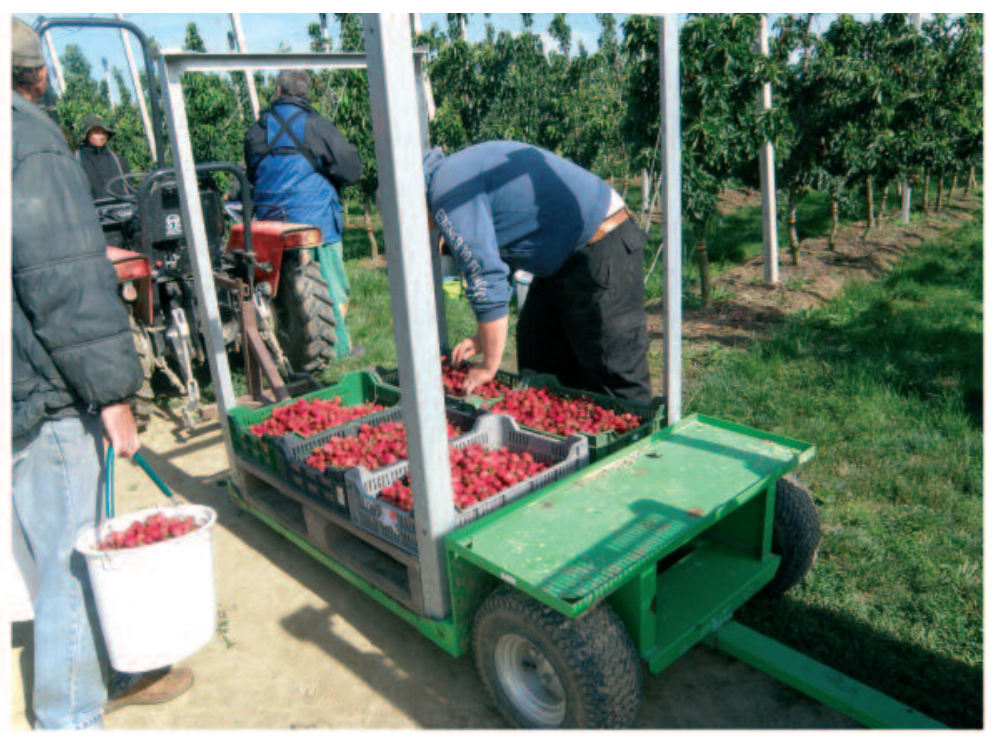

Fig. 2: The controlled takeover of the cherry and collection in bins 


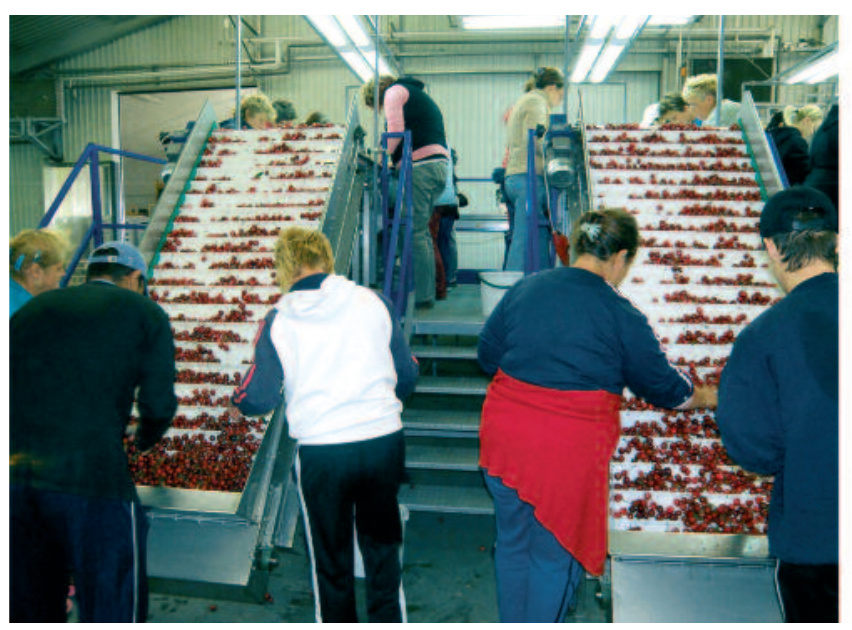

Fig. 3: Feeder belts

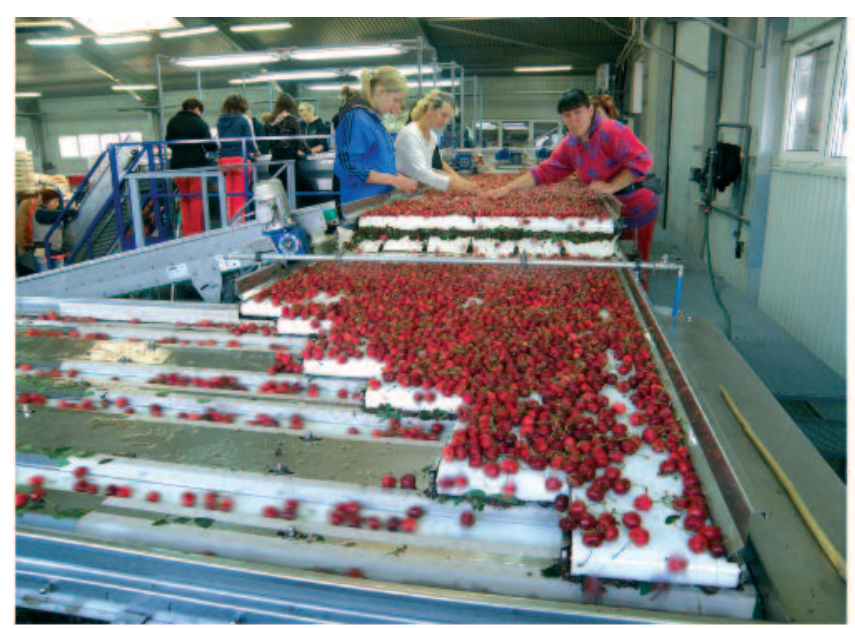

Fig. 5: Transverse collecting belt

For the automatic recording of the size the fruit must pass through in a row under the measuring unit. It is ensured by the ranging belts (Fig. 6).

The ranging belts have an important task; only discrete fruit movement is possible here, as twin cherries are caught up and the movement of the line is stopped, so constant supervision is needed here (Fig. 7).

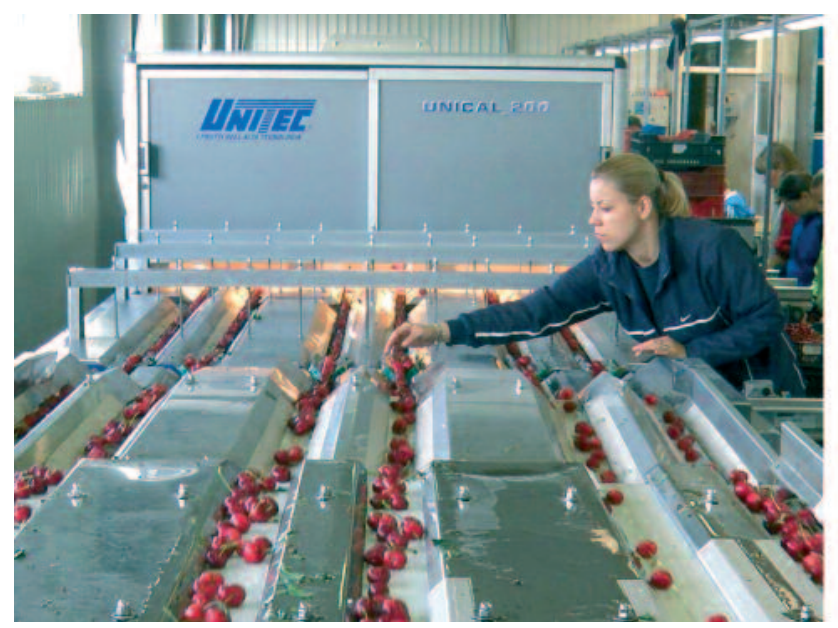

Fig. 7: Supervision of the ranging belts

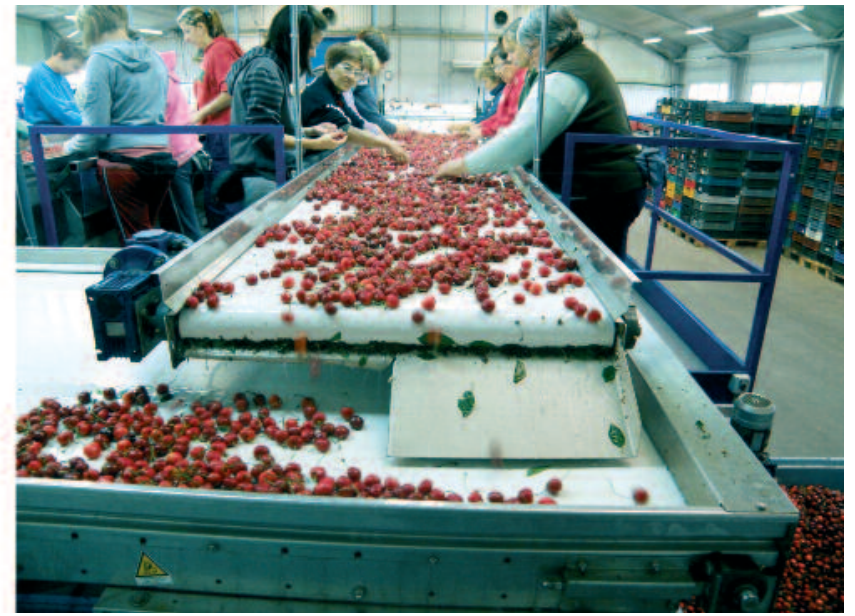

Fig. 4: Longitudinal sorting belts

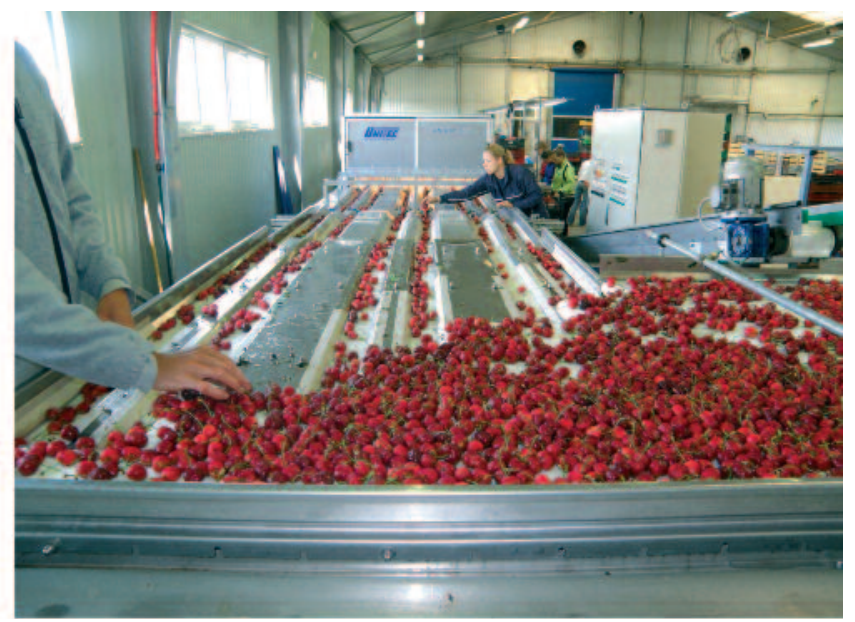

Fig. 6: Ranging belts

The most important part of the sorting machine is the UNICAL-200 electronic unit, which was developed for the assortment of small fruit and vegetables (cherries, sour cherries, olives, cherry tomatoes, etc), according to size and color. Size limits of the measuring unit are12 / $40 \mathrm{~mm}$. Its productivity is 30 fruit per second, per line, so the sorting machine can assort 108.000 fruit per hour, per line.

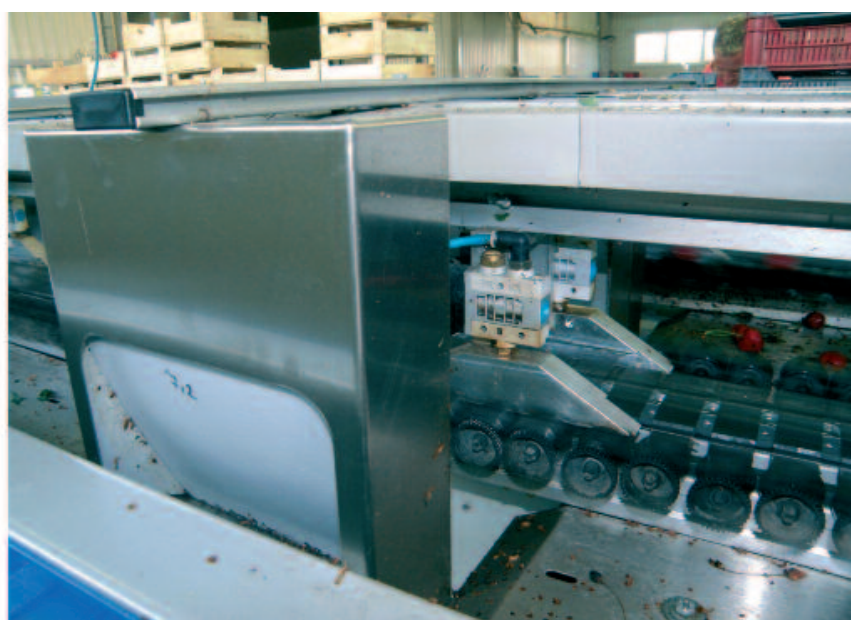

Fig. 8: The air separation units 


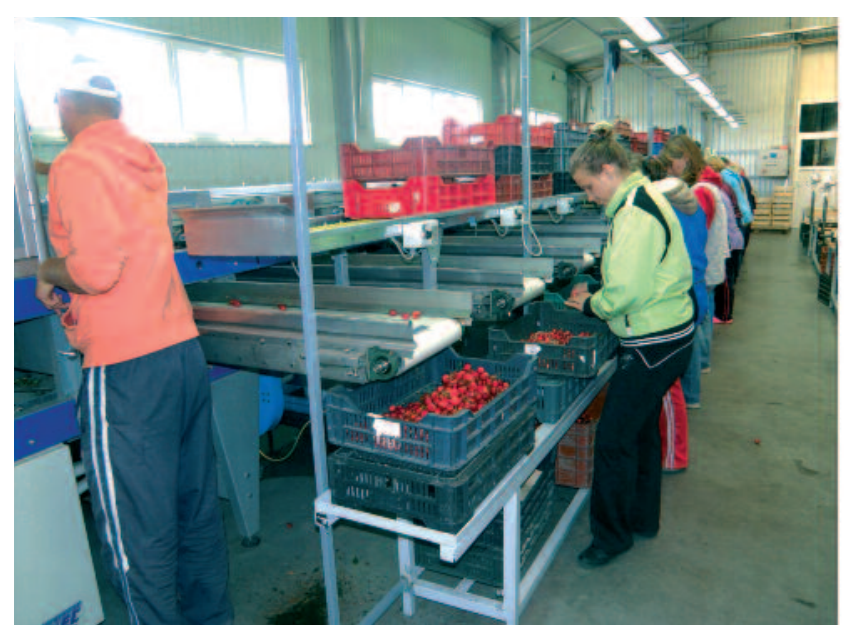

Fig. 9: The sorted product

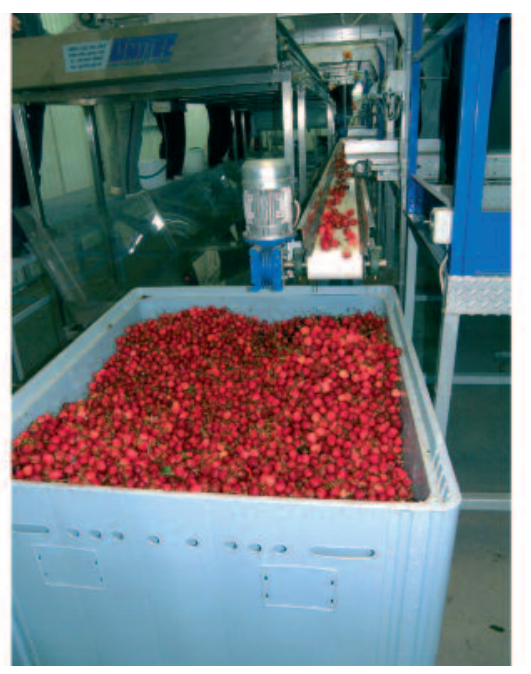

Fig. 11: Collection of the damaged fruit and those without stems

The machine is manufactured in $1,2,4,6,8$ lines versions. The tested machine is a 6-line version, which is capable to assort 648000 fruit per hour, with appropriate conditions. The color classification is carried out according to the average or the percentage evaluation.

The color and size categories, selected by the electronic unit, are blown dawn from the line with the pneumatic unit at a location, determined by the program (Fig. 8).

To avoid damages the fruit is impacted to soft, sloping plates. These plates direct the fruit to longitudinal conveyor belts which transport them into the appropriate bin. Workers, responsible for exchanging the bins make further sorting to select damaged fruit (Fig. 9).

The machine is controlled by a computer adjustable for different programmes (Fig. 10). In the examined situation the sorting was done in three size fractions: $24-26 \mathrm{~mm}, 26-28$ $\mathrm{mm}, 28-30 \mathrm{~mm}$. A size category could have been sorted on more than one belt. Each size category was divided into light or dark categories, according its color.

A separate line (Fig. 11) is used to collect the damaged fruit and those without stems; these are sold as mash raw material.

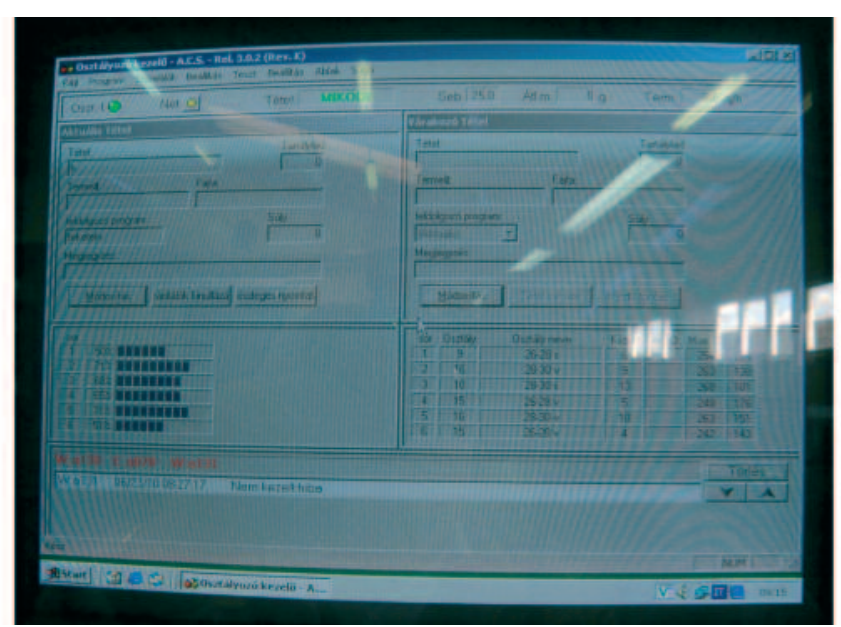

Fig. 10: The graphical user interface (GUI)

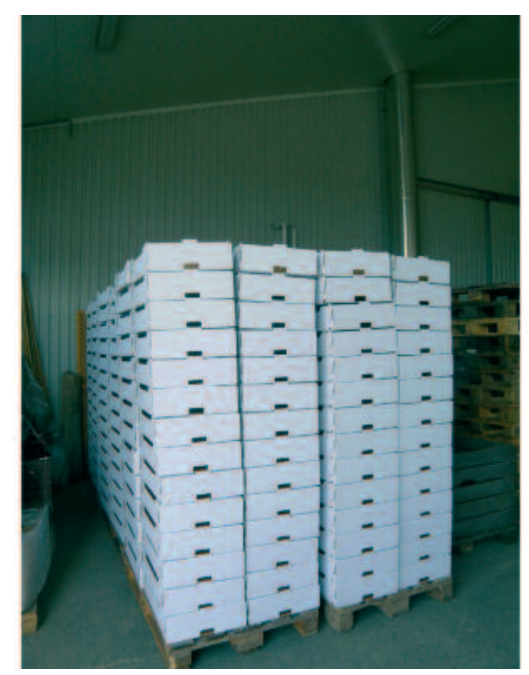

Fig. 12: Paper bins for the transport

\section{Packaging and transportation of the cherry}

The fruit then transported to the point of use in paper (Fig. 12) or plastic (Fig. 13) bins.

The folding of paper bins is made locally, while the plastic bins are ready to use (Fig. 14). Both types of bins have reinforced corners. The plastic bins are more expensive, however, more water-resistant and better withstand the vicissitudes of transport.

\section{Assessment of the sorting process}

Examinations were carried out to determine the quality of the sorting machine.

The main objectives of the examinations were to determine

- the extent to which the machine can sort the correct size categories,

- the average size of each size categories,

- the size distribution of the fruit,

- the smallest and the largest fruit size that occur in each category, 


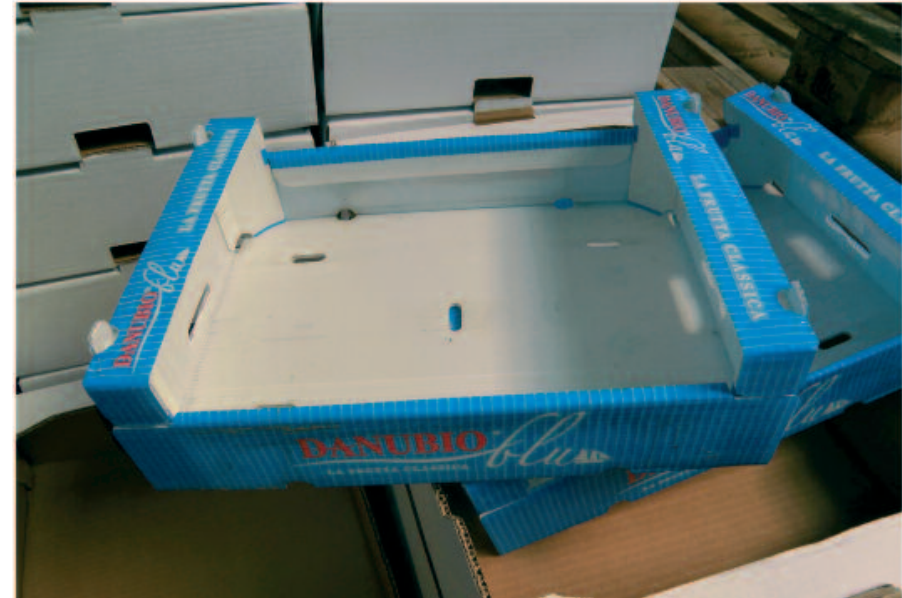

Fig. 13: The plastic bins

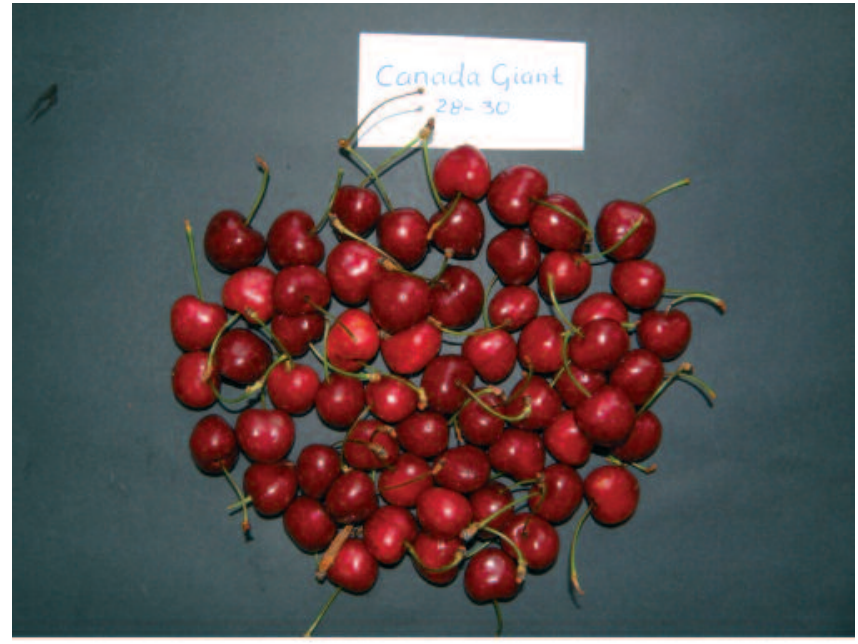

Fig. 15: The 28-32 mm size category of Canada Giant

- the proportion of fruit within the size category,

- the stone-pulp ratio in each size categories.

The following properties were measured:

- the fruit was measured in three orthogonal dimensions (width, it is often called diameter, height, this size is often called length, and thickness). A digital slide gauge with an accuracy of $0.01 \mathrm{~mm}$ was used to measure the sizes.

- the mass of each sweet cherry was measured by an analytical balance, with an accuracy of $0.001 \mathrm{~g}$.

- the mass of the stones with the same analytical balance,

The samples were photographed for subsequent image processing.

From the measured data we determined:

- the smallest and largest values of the three sizes in each size category,

- the average value of the three sizes of the sample,

- the standard deviation of the three sizes of the sample,

- the distribution of the three sizes of the sample,

- the stone-pulp ratio of the sample.

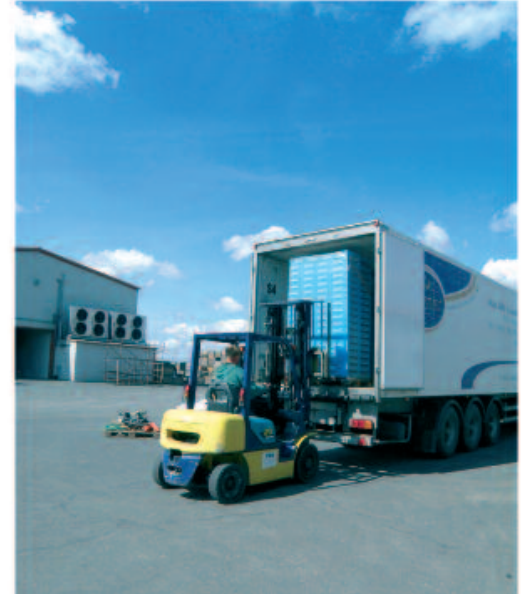

Fig. 14: The take over of the plastic bins

The Alma 2000 Ltd., Nagykutas, which operates the sorting machine, provided enough cherries for the measurements. From each variety $50-50$ cherries were chosen according to the sampling standards. The $28-32 \mathrm{~mm}$ size category of Canada Giant is shown in Fig. 15.

The measurements were carried out in the material testing laboratory of the Department of Agricultural Machinery, Institute for Land Utilization, Technology and Regional Development, Faculty of Agricultural Science, Debrecen University.

\section{Results}

The measuring data are summarised in tables and shown in figures.

\section{Width}

The average values of the widths of the samples are given in Table 1.

Table 1: The average values of the widths (mm)
\begin{tabular}{|l|c|c|c|}
\hline Canada Giant & $24-26$ & $26-28$ & $28-30$ \\
\hline Min. & 21,90 & 22,85 & 25,30 \\
\hline Max. & 26,23 & 27,18 & 29,75 \\
\hline Average & 23,40 & 24,88 & 27,29 \\
\hline Stand. deviation & 1,00 & 1,03 & 1,08 \\
\hline
\end{tabular}

From the data given in the table it can be concluded that:

- the average width is $92-94 \%$ of the average value of the size category and does not reach it in any case;

- the smallest sizes are under the minimum of the size category in each case, in fact $88-91 \%$ of that;

- the average values of the largest sizes are greater in one case; however they are close to the maximum of the size category in other cases.

The width distribution of samples of the tested fruit with the given size category are shown in diagrams. 
- Fig. 16 shows the distribution of the sample with $24-26 \mathrm{~mm}$ size category. It can be seen that $80 \%$ of the sample is within the given size category.

- Fig. 17 shows the distribution of the sample with $26-28 \mathrm{~mm}$ size category. It can be seen that $76 \%$ of the sample is within the given size category.

- Fig. 18 shows the distribution of the sample with $28-30 \mathrm{~mm}$ size category. It can be seen that $73 \%$ of the sample is within the given size category.

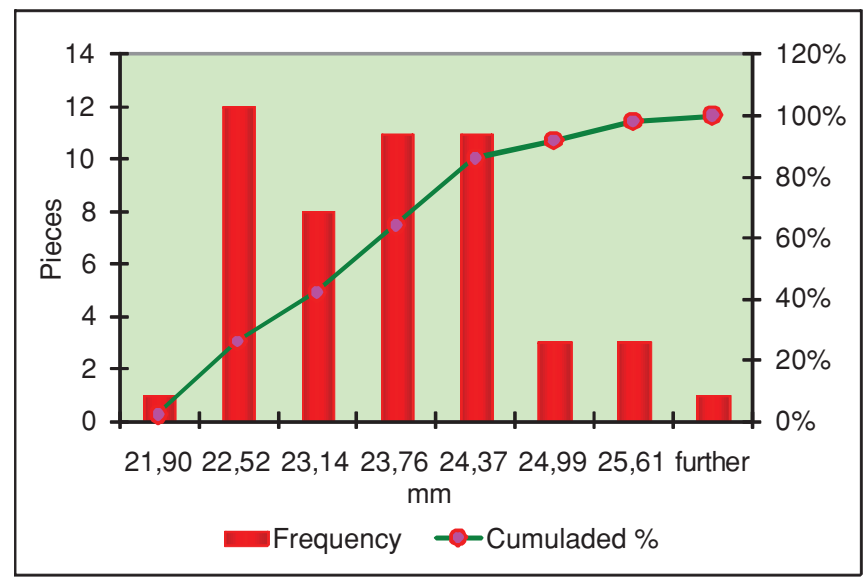

Fig. 16: The distribution of the sample with 24-26 mm size category

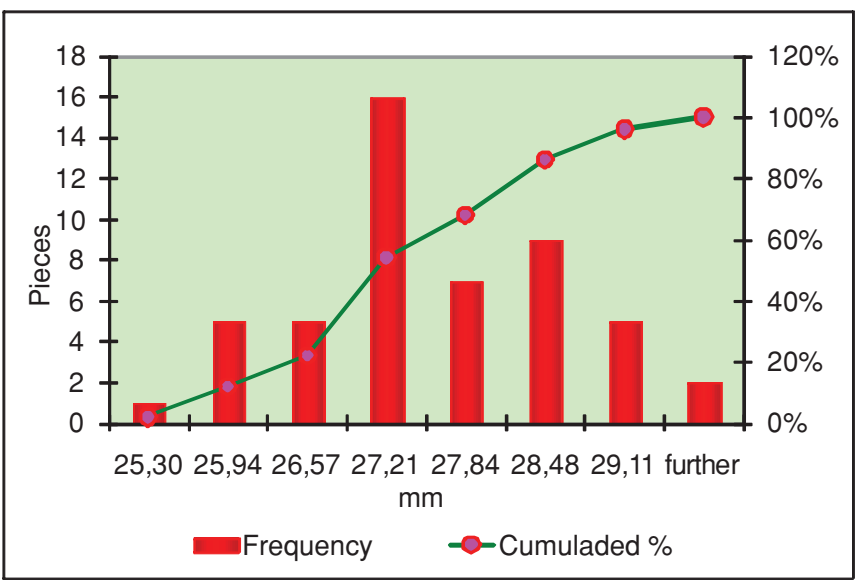

Fig. 18: The distribution of the sample with $28-30 \mathrm{~mm}$ size category

Only the distribution of the width is presented in the form of diagrams in present publication, as according to our measurements in the case of variety Canada Giant consistently the width was the largest size, and that is the size which is determined by the UNICAL-200 measuring unit of UNITEC sorting machine. However, the results for the other properties (height, thickness, mass, stone mass) are given in tables, so that analyses could be done.

\section{Height}

The values for the heights of the samples are given in Table 2.

From the data given in the table it can be seen, that:

- the average values of height are $88-91 \%$ of the average of the size category, and do not reach it in any case;

- the average values of the smallest size are $85-87 \%$ of the minimum of the size category and remain under it in every case.

- the average values of the largest size are $91-96 \%$ of the maximum of the size category and also remain under it in every case.

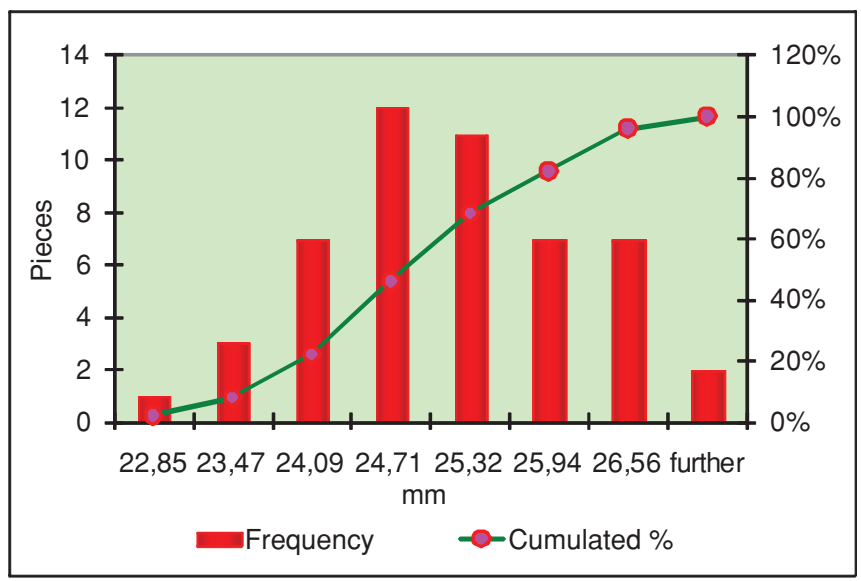

Fig. 17: The distribution of the sample with $26-28 \mathrm{~mm}$ size category

Table 2: The average values for the heights ( $\mathrm{mm})$

\begin{tabular}{|l|c|c|c|}
\hline Canada Giant & $24-26$ & $26-28$ & $28-30$ \\
\hline Min. & 20,91 & 22,15 & 23,72 \\
\hline Max. & 24,97 & 25,48 & 28,08 \\
\hline Average & 22,86 & 23,82 & 25,48 \\
\hline Stand. deviation & 0,99 & 0,86 & 1,13 \\
\hline
\end{tabular}

\section{Thickness}

The values for the thickness of the samples are given in Table 3.

Table 3: The average values for the thickness ( $\mathrm{mm}$ )

\begin{tabular}{|l|r|r|r|}
\hline Canada Giant & $24-26$ & $26-28$ & $28-30$ \\
\hline Min. & 17,47 & 17,75 & 20,03 \\
\hline Max. & 20,48 & 22,09 & 24,68 \\
\hline Average & 19,21 & 19,64 & 21,60 \\
\hline Stand. deviation & 0,73 & 0,86 & 1,00 \\
\hline
\end{tabular}

From the data given in the table it can be seen, that:

- the average values of thickness are $73-77 \%$ of the average of the size category, and do not reach it in any case;

- the average values of the smallest size are $68-73 \%$ of the minimum of the size category and remain under it in every case;

- the average values of the largest size are $79-82 \%$ of the maximum of the size category and also remain under it in every case.

\section{Individual mass}

The values for the individual mass of the samples are given in Table 4. 
Table 4. The average values for the individual mass (g)

\begin{tabular}{|l|c|c|c|}
\hline Canada Giant & $24-26$ & $26-28$ & $28-30$ \\
\hline Min. & 5,36 & 5,90 & 7,85 \\
\hline Max. & 8,61 & 9,02 & 12,13 \\
\hline Average & 6,37 & 7,37 & 9,55 \\
\hline Stand. deviation & 0,66 & 0,70 & 1,00 \\
\hline
\end{tabular}

From the data given in the table it can be seen, that:

- the average mass of $24-26 \mathrm{~mm}$ size category is $6,37 \mathrm{~g}$, the $26-28 \mathrm{~mm}$ size category $7,37 \mathrm{~g}$, and the $28-30$ $\mathrm{mm}$ size category $9,55 \mathrm{~g}$;

- the minimum fruit mass, $5,36 \mathrm{~g}$, was measured in the 24-26 mm size category, and the maximum, $12,13 \mathrm{~g}$, in the $28-30 \mathrm{~mm}$ size category.

- the standard deviation ranged from 0,66 to 0,96 .

\section{Individual stone mass}

The values for the individual stone mass of the samples are given in Table 5 .

Table 5. The average values for the individual stone mass (g)

\begin{tabular}{|l|c|c|c|}
\hline Canada Giant & $24-26$ & $26-28$ & $28-30$ \\
\hline Min. & 0,25 & 0,27 & 0,34 \\
\hline Max. & 0,50 & 0,49 & 0,47 \\
\hline Average & 0,35 & 0,37 & 0,40 \\
\hline Stand. deviation & 0,05 & 0,05 & 0,40 \\
\hline
\end{tabular}

From the data given in the table it can be seen, that:

- the average stone mass of 24-26 mm size category is $0,35 \mathrm{~g}$, the $26-28 \mathrm{~mm}$ size category $0,37 \mathrm{~g}$, and the 28-30 mm size category $0,40 \mathrm{~g}$;

- the minimum stone mass, $0,25 \mathrm{~g}$, was measured in the 24-26 $\mathrm{mm}$ size category, and the maximum, $0,50 \mathrm{~g}$, in the same size category.

- the values for stone mass do not follow the size categories in all respects.

\section{Stone-pulp ratio}

The average values for the stone-pulp ratio of the samples are given in Table 6.

Table 6. The average values for the stone-pulp ratio (\%)

\begin{tabular}{|l|c|c|c|}
\hline Canada Giant & $24-26$ & $26-28$ & $28-30$ \\
\hline Min. & 4,15 & 4,12 & 3,29 \\
\hline Max. & 8,03 & 7,27 & 5,24 \\
\hline Average & 5,80 & 5,32 & 4,37 \\
\hline Stand. deviation & 0,86 & 0,76 & 0,55 \\
\hline
\end{tabular}

From the data given in the table it can be seen, that:

- the stone-pulp ratio is the most unfavourable in the 24-26 mm size category, with 5,8\%;

- the stone-pulp ratio is medium value in the $24-26 \mathrm{~mm}$ size category, with $5,32 \%$;
- the stone-pulp ratio is the most favourable in the 28-30 mm size category, with 4,37\%;

The stone-pulp ratio of the individual categories can be seen in Fig. 19.

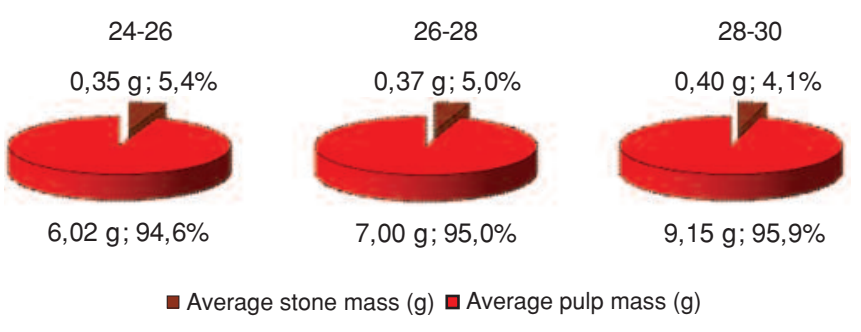

Fig. 19 The stone-pulp ratio of Canada Giant in the individual categories

\section{Conclusions}

The measured sizes of the samples remain under the values of the size categories;

$73-80 \%$ of the tested samples is within the given size category;

The stone-pulp ratio is the most unfavourable in the smallest size category $(5,4 \%)$ and the most favourable in the largest size category $(4,1 \%)$.

Further examinations are required to find out why the machine sorts smaller fruits into each size category, consistently.

\section{Aknowledgement}

This work was financed by NFÜ TECH_08-A3/2-20080373 grant.

\section{References}

Csizmazia, Z. \& Polyák, N. I. (2004): Physical Properties of Green-Pea Seeds. IAMFE-RUSSIA 2004. 12th International Conference and Exhibition on Mechanization of Field Experiments. St. Petersburg-Pushkin, Russia. Proceedings, 371-375.

Csizmazia, Z. \& Polyák, N. I. (2004): The Physical Characteristics of Hemp Seed. Hungarian Agricultural Engineering. 17: 60-62.

Polyák N.I. (1998) Some Physical Characteristics of Seeds. IAMFE-ARGENTINA, 98. First Latin American IAMFE Conference and Exhibition. Proceedings, 247-255.

Polyák, N.I. \& Csizmazia, Z. (2003): Physical Properties of Seeds of Vegetables. Hungarian Agricultural Engineering, 16: 35-37.

Polyák, N.I., Csizmazia, Z. \& Ancza, E. (2010): Some physical properties of sweet cherries. International Journal of Horticultural Science. 16 (1): 63-70.

UNICAL 200 Cherry Grader. http://www.edp.com.au

A zöldség- és gyümölcsfeldolgozás technológiái. (Processing technologies for vegetables and fruits) http://www.chemonot.hu

Magyar élelmiszerkönyv 1-4-899/87/1 számú elöírás cseresznye és meggy minőségére. (Hungarian Food Book Nr.1-4-899/87/1 regulation for the quality of sweet and sour cherries) http:// www.omgk.hu 